\title{
Interview with Alberto Pérez-Gómez
}

\author{
SAUNDRA WEDDLE Drury University
}

MARC J. NEVEU California Polytechnic State University, San Luis Obispo

This interview took place in August, 2010.

MJN

One premise of this theme issue for the JAE is that the relationship between history and design should be activated. Implied in this premise is either a complete abandonment of history, or general dissatisfaction with approaches to history that focus on a canon that is considered as little more than a pattern book organized by typologies or styles. How would you characterize the relationship between history and praxis, specifically in the education of an architect?

APG

These are very serious questions!

There is some real reason for the dissatisfaction that exists. It stems from a general misunderstanding of what history can provide the future or practicing architect. The origin of this problem can be pinpointed historically. This is useful because it means that the situation we face has not always been the same. There are many aspects to this. The first issue is that our understanding of history as styles or typologies comes from the beginning of the nineteenth century. One can find the origins of this by tracing its own precedents. Knowing this, we are not condemned to understand history in those terms. This moment reduced the field of architectural history to a history of buildings organized according to formal taxonomies or stylistic characteristics. This was very unfortunate but it has stuck, generally, in the teaching and practice of architecture. When one understands the history of architecture in those terms it becomes easy to dismiss it because we don't go very far with it. There is another aspect to this issue, which is that prior to the eighteenth century, architects had relatively little use for history because, generally, Western culture (as well as other cultures, but certainly our own Western culture) believed that architecture's meanings came from an almost direct mapping or reflection of a cosmic order that was trans-historical itself. The use of history for someone like Palladio or anyone prior to that time was limited. There were chronicles, myths, and stories, narratives that modulated appropriate actions, but practice was not "historical" in the sense that it built upon the past towards some progressive future, potentially becoming prescriptive or instrumentalized. So this creates the problem. In a certain way, the understanding of history by historians has been problematic since its inception. So that is one of the major tasks that we have to try to grapple with.

How does one then go about reconnecting and finding appropriate ways to connect history to design? One must start by understanding the proper nature of history as hermeneutics. What is at stake is more than form. Architectural programs have political consequences. What one learns from historical precedents, from the stories we tell about the stuff that we admire in the past, is that it can be translated into our own questions and allow us to act in an ethical way. History does not orient us very much about what forms we should use. It is much more about the appropriateness of our actions, which is probably much more important than the specific formal problems we usually identify as architects. 
SW

I wonder why you think the eighteenth and nineteenth centuries mode of engaging the past has persisted? Does it have something to do with the way we use history, culturally, or the way that architects in particular use history?

APG

Yes; from the beginning of the nineteenth century the relationship between the thoughts we have as architects and our actions have been construed instrumentally. It is something that was not always there. While this possibility was prepared through the history of Western philosophy since Plato, it only happens in practical fields like architecture, engineering or medicine in the beginning of the nineteenth century. Instrumentality dictates that we find ways to connect to historical precedent in precisely this way. Thus, all technological disciplines become more efficient but they also tend to ignore their foundation in relevant human questions, often failing in their tasks (like medicine that cures disease but becomes incapable of healing, or architecture that provides shelter but is incapable of dwelling). In the end instrumentalized history is futile because its intention is basically resolved in technology, and usually there are more expeditious ways of dealing with these questions than historical narratives.

MJN

I would like to continue the conversation by focusing more on the education of an architect. At McGill you have supervised graduate students for over twenty years. How should [architecture students] be educated in history and theory?

APG

Well, my work at McGill has been mostly with graduate students. Before, I was working in professional programs. I was directing a professional program [at Carleton] and that might be more to the point in fact. But to start with McGill, because it is a postprofessional program, I see my role as teaching teachers, which is really like a seconddegree kind of education. I concentrate on those things that are lacking in the first degree, whether it is a B.Arch or professional M.Arch. I try to make up for the basic questions that have not been asked in a professional education that might allow a teacher to teach better. The issue of teaching a project within the Master's program is very interesting but I don't think we go very far. This might be something worth doing over a whole year-doing a whole program around this issue of the connections between thinking and making. However, the emphasis is on those things that are evidently lacking in professional education.

When I was at Carleton as Director for three years, I was very young and I had a very simplistic model: that I should profit from the wonderful experience of Cooper Union, because I always admired that place even though I was never connected to it. I admired John Hejduk and the pedagogy there. But I also gave it a very serious ground in history and theory, or as serious as I could, given the limitations of a professional program. There, I taught what I teach at the Master's level here [at McGill] in three hours per week for the whole year and to the whole school, looking at the history of architectural theories, and I 
got some interesting results. We had some very serious theses that managed to bring together a love for making with serious meditative thinking.

Now I wonder if such marriage of skill and content is possible in the shortened programs that we all have to deal with. We have gotten rid of the five-year [B.Arch] programs that I thought were fantastic, where you could really prepare professionals, with some time to travel, some time to discuss things, taking some good courses. Now everything is in a hurry and we have to deal with accreditation checklists and I find it far more difficult. I am, of course, generalizing terribly. I know programs are quite different, but in general I regret that we have shortened the time that we take to train professional architects. It takes time because the transdisciplinary problems have to be approached from "within"' (it is not enough to take courses in the arts or philosophy). It is impossible to do it fast.

MJN

In undergraduate education we deal with these questions at the professional educational level. Accreditation, however, doesn't require that we teach survey courses. That said, so much of history is still taught through the survey. What do you think is the best mode of delivery so that these questions you've talked about can be asked?

APG

Well, the first thing is for the teacher to identify those questions for himself or herself. It is always very personal. Identifying those questions is crucial-much more than covering material or simply conveying information. The survey has been shown to be a very problematic model and yet, as you point out, we keep doing it. Everywhere there is the sense that we have to cover material. One way to get at the questions is to filter our heritage through the professors' fascinations, through the questions that really matter to us, so that the historical topics are delivered through these questions rather than in an anonymous way [as when one simply conveys "facts"].

However, to do this effectively, one must acknowledge that the disciplinary boundaries between architectural history and other aspects of historical phenomena, including the history of science, the history of philosophy, the history of mentalities, and material histories, are not solid. One of the big problems is that even among architectural historians there is the sense that one has the "right" methodology; that this may be the only one that is valid and somehow this excludes other things. I vehemently support breaking down these barriers.

For me, it has been crucial to connect the history of religious ideas, the history of science, the history of philosophy to thinking about architecture and to the thoughts of architects throughout history. That is the only way one can articulate the questions of our predecessors that resonate with our own questions and that make history relevant. Otherwise it is always a thing of the past. Methodologically, it is not a bad idea, for example, to structure lectures where you deal with historical material and connect it, even force it into connections with present questions and open up the debate and try to understand how this historical background gives guidelines and sets precedents on how things are not as new as they seem to be. This is always the big problem. We think we have to reinvent the wheel and we don't. There are thematic connections, but there are also questions that show how things are resonant and how one can learn from these historical examples. 
Demonstrating the "resonance" between Hans Scharoun's amazingly inventive Berlin Philharmonic Hall and a Greek amphitheater in the mountains, for example, might be invaluable to a young student who believes in the unqualified merits of novelty.

I do believe, however, that there is something to be said for chronology, for knowing that Gothic comes after the Romanesque. As a student I remember getting lost if I didn't have this basic information. It is a negotiation. Basically the survey could be a couple of weeks reading Pevsner, or something more recent, at least to know where things are. But after that the questions should guide the delivery of the material and the professors [should] find those resonances, even if we are not completely sure about the connections. Even merely opening the questions can be an excellent pedagogical tool.

\section{SW}

In your view, are there fundamental, nonnegotiable principles of architectural history that anchor the discipline and distinguish it from others?

APG

Yes, I think there are, but this is a long lecture as well. Architecture does offer something specific. It has something to do with us finding a place that is ordered, that speaks back to us, that allows us to dream, that orients us, as I often say, like a metaphysics that is made into material, that allows the inhabitant / participant to find his or her own place in the world in relation to an institutional framework, wherever we may be in time and space. There is something very basic that architecture does offer and has offered throughout history because the questions that architecture addresses are resonant with the bigquestions of mankind. There are resonances with religion, with science, and with philosophy particularly. Architecture does address those questions and provides answers that are particular to specific times and places and that allow humanity to live well, let's say, and pass on to others the savoir vivre, a kind of wisdom that we may profit from as the heirs of these traditions and that we often disregard completely, particularly in modern times. This, of course, begs questions.

As modern individuals we are all very arrogant; we feel that we can live in our own universe and that we are almost unaffected by physical environments. We think we can live in our computer screens. But in the end, the physical spaces that we make really do matter. They contribute to our wellbeing or our pathologies. That is where history matters. If we don't learn from those precedents, we have nowhere to look because we have nothing else that we share today. We have all of our little beliefs and half beliefs. We don't share a cosmology, we don't share a religion and so we inhabit a fragmented and cosmopolitan world. The only way to find appropriate ways of action is by looking at history.

\section{SW}

You mentioned that architectural history has an obligation to provide a kind of framework or orientation that we can use to compare to our experience to understand it more fully. I wonder about the practice of the architectural historian. Do you think there are guiding principles that are nonnegotiable for the historian? 
Of course, I believe there is better history than other history. Histories are stories after all. Histories that try to be objective and factual could be useful but I always miss the dimension of interpretation. I don't know if I would call this "non-negotiable," but my preference is to frame architectural history in terms of hermeneutics. A way of looking at history that comes from the philosophical tradition of the twentieth century, particularly [Martin] Heidegger, [Hans-Georg] Gadamer, and [Paul] Ricoeur, who help the professional historian write a more helpful history. Why? Because in this kind of framework, the issue is to foreground interpretation. Interpretation is basically how we get at truths. And interpretations mean that we valorize the questions. We first find the questions that are important to each one of us and then we understand their importance in terms of their cultural significance. Then we look at the material and interpret it through these questions so that it can speak to us. It is what [Gadamer] calls a "fusion of horizons" bringing that which is far, near, while understanding that you can never be a Roman, that you can never be a Greek, that you can never be monastic. There is always going to be this distance, but this distance should be celebrated and used to foreground our questions so that the material becomes useful for us. Of course, this is very much at odds with the idea of a historian who thinks of the discipline as a scientific endeavor that is going to find the objective facts about one thing or another. That is futile waste of time (even though I use many of these books because people do some very serious work and spend all of their lives working in archives and this is very, very useful.) But in the end, for me, as an educator of architects, what matters is this interpretative framing of the historical material that connects in a dialogue with present questions.

SW

An issue that interests us is that the discipline of architectural history is not autonomous. Increasingly, as you've said, it relies upon and appropriates from the resources and methods of other disciplines. What, in your opinion, has been gained by architectural historians appropriating from other fields of inquiry?

APG

For me, this is simply real architectural history because if architecture is a manifestation of culture, then you cannot parcel out these things and consider that the history of architecture is simply the history of buildings and leave out gardens, and leave out the history of stage set designs, and leave out the history of ideas. It is kind of obvious, but it is very demanding. For architectural historians of an art historical bent, let's say, there seems to be resistance to opening up the field like that. Of course it is difficult, but we have no other option. Otherwise we are condemned to irrelevancy.

SW

A question that takes the discussion of disciplinary autonomy in a different direction: I wonder how you think the aims and methods and even the work of historians differs from those of the critic.

APG

This is also a question of disciplinary boundaries. With some rare exceptions I've seldom written about someone who is alive. It doesn't mean that the work and the kind of 
writing I do about someone like, say, Guarini is different than that of a critic, necessarily. One can certainly speak about contemporary works in a way that contextualizes them and that connects them to other disciplines in similar ways that one might do with a historical artifact. Nietzsche clearly recognized that relevant history is in some measure "critical." I think the disciplinary distinctions are mostly artificial.

MJN

I'd like to flesh out this question of historical relevance a bit more. I'll do so by bringing up Tafuri. Manfredo Tafuri's critique of the operative historian was focused on Pevsner and Giedion who, in his view, began with a set of beliefs and then selectively constructed a history to support those beliefs. All historians intentionally select and omit evidence, and all histories are interpretive and constructed. How does one make history relevant without being operative?

APG

You know, with Tafuri every word is coded back into some kind of left-wing position. The danger for me is instrumentality. I'm not sure how Tafuri's understanding of operative history and instrumental history in the sense described before would relate or differ. Do you have some idea about that?

MJN

Tafuri, as I understand, was critiquing Pevsner and Giedion because they had an answer and then went back into history to support that answer. Tafuri was critical of this, but his response was almost to say, "I don't care that much about the contemporary situation. I am going to go back to history." His last work on Renaissance Venice, for example, has little to do with contemporary issues. But there is that great possibility that history might matter, that it might be relevant. So rather than being operative and rather than disappearing into history, is there a way of making history relevant?

APG

The way I remember this problem, the issue is to preserve a rationality or objectivity of the historical narrative, and this always led to a suspicion about hermeneutics or foregrounding questions that forces the connections to the present.

For me, the way to deal with this problem is rather to disallow that there is a rationality at work in historical processes, or a dialectic at work in historical process, and to understand that in this mass of material, evidence, and touching moments that we get from the past, there are connections that are self-evident for each of us, which we have to learn to cultivate and from which real questions that matter in the present could stem. There is this connection between hermeneutics and phenomenology. We must learn to recognize the importance of what matters to each one of us, questioning "common sense" skepticism that always defers to the opinions or the objective facts of others. Believing in the evidence of your experience-this, for me, is very crucial. It is also at odds with the homogenizing that happened in the aftermath of deconstruction where historical narratives and valorization were taken down to the lowest common denominator. The fact is that certain artifacts move you and bring forward questions and connect in an ahistorical way. We all have access to this. It is a question of exposure. This is part of what 
good architectural teachers should do for their students. It is important to understand that these moments of epiphany matter, to cultivate them, and to valorize them. Then we can construct stories that are incredibly valuable. I don't think that the past is valuable just because it is past. This connection between phenomenology and hermeneutics is very important.

SW

Traditionally, the product of the historian's work has been the publication or conference presentation, sometimes a book review; today, the historian's work also finds an audience in blogs, which are becoming an important component of architectural discourse. There may be images or drawings, but the essential product of the architectural historian's work is the text. What other forms might the work of history take? On what terms should these forms be evaluated?

APG

History is basically stories; otherwise maybe we are into some other forms of expression. Maybe some historians want to make documentaries, to use other media; it is basically about telling stories. What is most important, however, is dialogue. Part of the problem with the media that you mention is that sometimes it is forgotten that the moment of communication is really dialogical. This is crucial.

I have tried very hard to engage people in oral communication. Here at McGill we write a little bit, but not as much as other graduate programs. We are always talking, always presenting, always discussing. Plato is, for me, crucial here. He is at the beginning of the technology of writing applied to philosophy in the dialogues, and yet they are dialogues. He says on more than one occasion that we have to be careful with the written word because it is an instrument of forgetting, and that the written word is not real knowledge. Real knowledge happens in the dialogical moment, in the moment of assent when we meet to communicate face to face. The historian must not forget that dialogue is where history happens, where you make present what is important here and now. The other forms of writing are very interesting, sophisticated, and crucial in a way. I am not claiming that we should get rid of books. What has priority is the oral, the word as spoken. Or alternatively, for the student of history, to receive the written word dialogically, not passively.

SW

Some historians argue that the exhibition can be a mode of history. [In the context you describe] the text makes the exhibition a work of history; the works that are exhibited are like the historical evidence that [the historian] considers in a more traditional work of history.

APG

The question of exhibitions opens up a whole new field of issues. Art and artifacts have a discursive capacity that operates on many levels. It is a complicated problem. For example, how does an artifact express? It can tell a literal story, but it can also say other things. The juxtaposition of a Piranesi drawing with a photograph by Gordon Matta-Clark in an exhibition constitutes a discursive utterance that is very powerful, for example (Figures 1 and 2). But, is it history? I am not sure. It is probably better to stick with the difference 
that Ricoeur sets out, differentiating and identifying relationships between narrative and fictional forms with historical forms. Fiction and history have something in common. Both tell stories but have a different obligation. History has an obligation for what has been and has a discursive obligation. Fiction is something else.

This is not to diminish fiction. On the contrary, fiction, for example the juxtaposition of Piranesi with Gordon Matta-Clark, might actually reveal something more significant about reality than a chronicle about things past. Aristotle certainly thought so, when he said that fiction was more "philosophical" than history. The problem is complicated because everything is discursive and language is given with being, as Heidegger might say.

But it is important to differentiate what we do as historians. We have an obligation to those things that have been. It is our heritage. That does not mean you don't interpret, but rather that you interpret with the knowledge that this responsibility is paramount. I am fascinated with the discursive dimension of an exhibition but I don't think it is history.

SW

As a historian, your work considers architecture as much as the broader realm of cultural and intellectual history. Who is the audience for your work?

APG

I hope that the audience for my work is the architect-the future architect most likely. When I write, I imagine myself speaking to architects, not to philosophers or professional historians. However, once [my writings] are put out in the world they have different fortunes. My questions come from a simple disillusionment with the conditions of architectural practice in Mexico when I finished my education. I never wanted to become a professional historian or an academic. I studied for five years in a school with good design studios and a strong technical emphasis. I felt I was very badly prepared to practice because teachers preached modern architecture as a formal and technological dogma, without concern for historical precedents, aboriginal cultures or whatever was there. I found this was terrible and that is the reason I looked to broaden my horizons. I never went back and I became an academic; I always liked teaching, but my final decisions were circumstantial. Regardless, my questions, at the very root, have a professional concern. So I would hope that is my audience, but I know it often is not.

MJN

Alberto, you've touched on a lot of things that are important to me and I know are important to Saundra and we are very grateful. Maybe I could ask one last question. In your first book, Architecture and the Crisis of Modern Science, you diagnosed a "crisis" in Western culture. You defined a crisis as a "moment when it is unclear whether the patient will survive or succumb." It is twenty-five years later, has the patient survived?

APG

I think Husserl's "diagnosis" is still operative. We keep losing spoken (living) languages every moment, sacrificed to some universalizing ideal, encouraged by the promises of globalization: and this means a net loss for human culture. There is a growing interest in phenomenology in architecture, perhaps because the recent avant-garde architectural production is so dull despite its mannerisms. This is encouraging, but the 
state of architecture is very diversified. I'll tell you an anecdote. I am a member of that august body, the Royal Architectural Institute of Canada. Every year they send me a book with the Governor General's award for architecture. I have it here in front of me and I notice that all the work looks modern. There are no blobs or spiky crystals. It is actually quite good work, in general, sophisticated, really minimalist, simple, if you like, for lack of better words, orthogonal rather than this kind of craziness that we see every day when we get newsletters on the web. I have not yet been touched by much of this avant-garde stuff, other than the museum in Berlin by Libeskind, which I think is a rather remarkable thing. But most of the stuff leaves me very uninterested.

Yet, when I look around, even in our own school, formal craziness is always lurking. Often the use of digital tools is merely instrumental and forms are simply gratuitous, for the sake of novelty, following the fashions of biology or sustainability. Generally there is little evidence of the architects' primary concern with social and cultural issues, no acknowledgement of the primacy of the natural world (gravity is not negotiable-as Greg Lynn might think). Our cultures are certainly in big trouble and architecture reflects this condition. 


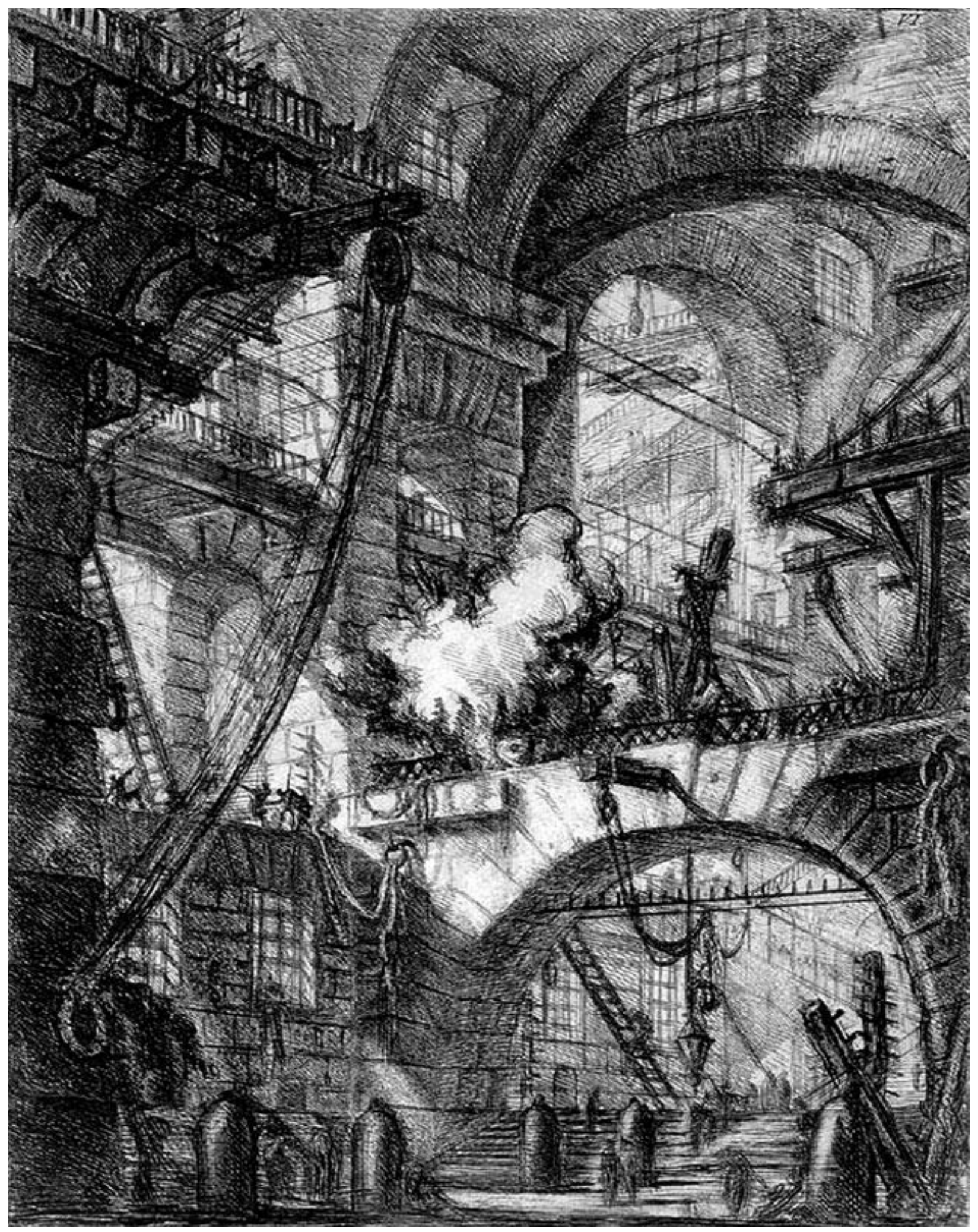

Giam bat tista Piranesi, "Plate 6" (second state) from the Carceri etchings (1761). 


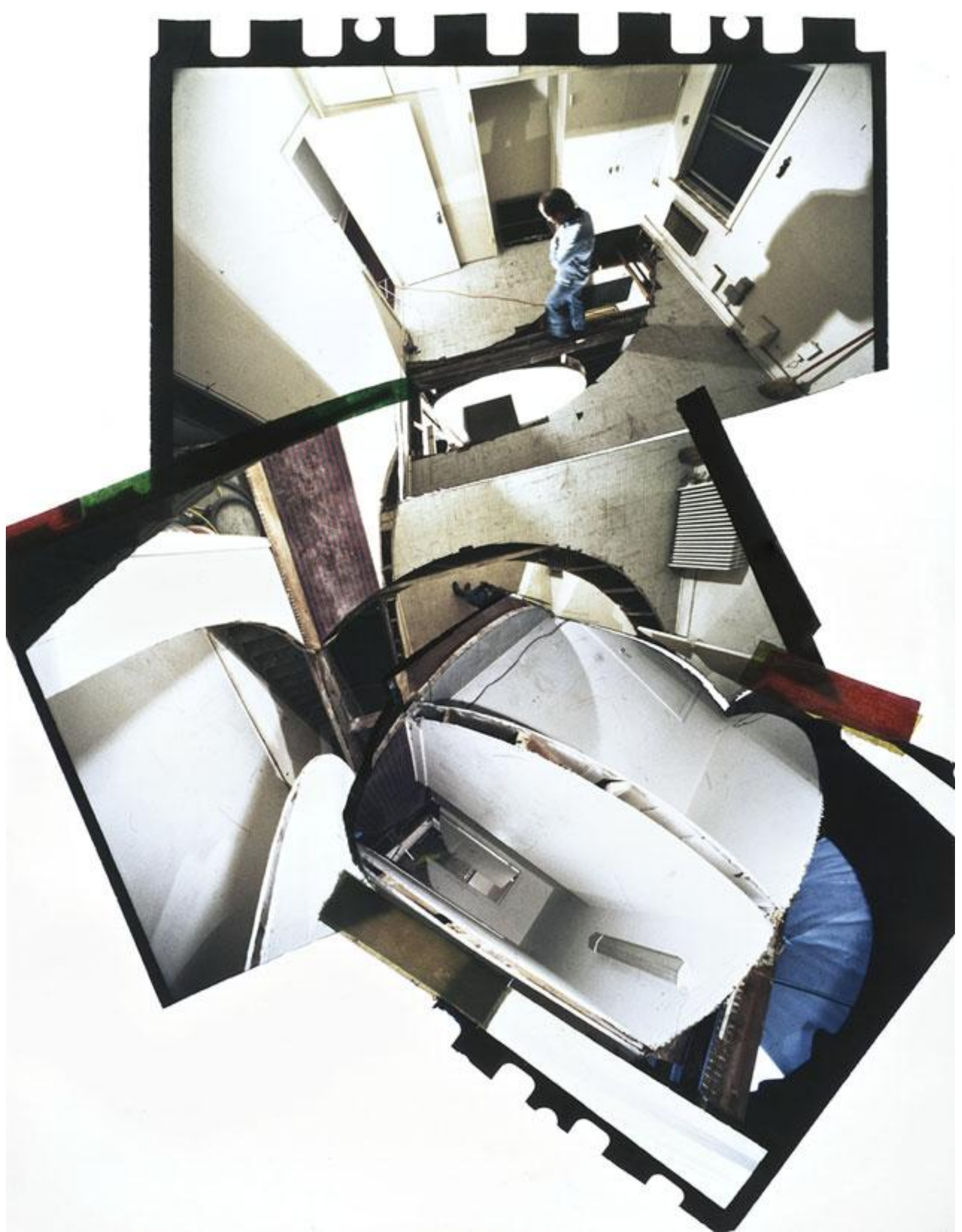

Gordon Mat ta-Clark, "Circus-the Carib bean Orange." Used by permission from the 2010 Est at e of Gordon Matt a-Clark / Artist s Rights Societ y (ARS), New York (2010). 